This is an electronic version of an article published as: Alexander, D. (1990). Bioregionalism: Science or sensibility? Environmental Ethics, 12(2), 161-173.

Environmental Ethics is available online at: http://www.cep.unt.edu/enethics.html. 


\title{
Bioregionalism: Science or Sensibility?
}

\author{
Donald Alexander*
}

\begin{abstract}
The current interest in bioregionalism, stimulated in part by Kirkpatrick Sale's Dwellers in the Land, shows that people are looking for a form of political praxis which addresses the importance of region. In this paper, I argue that much of the bioregional literature written to date mystifies the concept of region, discounting the role of subjectivity and culture in shaping regional boundaries and veers toward a simplistic view of "nature knows best." Bioregionalism can be rehabilitated, provided we treat it not as a "revealed wisdom" for the reconstruction of human society, but as a sensibility and environmental ethic that can infuse our work even as we make use of the functional regionalisms that increasingly shape people's consciousness. I conclude by citing Lewis Mumford's concept of a region as capturing the dialectical interplay of natural and cultural elements.
\end{abstract}

\section{INTRODUCTION}

The concept of bioregionalism, while having various antecedents, was first popularized in the mid-1970s by Peter Berg and Raymond Dasmann of the Planet Drum Foundation, an organization founded in 1974 to "pursue research and publish information on the relationship between human culture and the natural processes of the planetary biosphere."1 Berg was a longtime member of the California counterculture, and Dasmann, a noted ecologist, was a leading member of the International Union for Conservation of Nature and Natural Resources. The word bioregionalism appears to have been coined by a Canadian, Allen Van Newkirk, in 1974 in a research prospectus entitled "Bioregions: Towards Bioregional Strategy for Human Culture." This prospectus first appeared in the International Union's journal, Environmental Conservation, and was reprinted in CoEvolution Quarterly. Peter Berg likely picked up the term from Dasmann or from CoEvolution Quarterly. ${ }^{2}$

That the idea was ready to be born is shown by the appearance in 1975 of Ernest Callenbach's bioregional novel, Ecotopia, about an ecological nation in northern California, Oregon, and Washington which secedes from the United

* School of Urban and Regional Planning, University of Waterloo, Waterloo, Ontario, Canada $\mathrm{N} 2 \mathrm{~L}$ 3G1. Alexander is a doctoral candidate, with a special interest in bioregional economics. He recently completed a Master's thesis on an Ontario community's resistance to radioactive waste. The author thanks John Wadland and Jennifer Sells for their advice and encouragement.

1 Peter Berg, "Bioregions," Resurgence 98 (1983): 19.

2 James J. Parsons, "On 'Bioregionalism' and 'Watershed Consciousness,'” The Professional Geographer 37, no. 1 (1985): 4. 
States. A year later, David Haenke, now a bioregional author and activist, began making plans for holding an Ozark Community Congress, the first bioregional gathering of its kind. ${ }^{3}$

Kirkpatrick Sale offers perhaps the most concise definition of a bioregion as being "a place defined by its life forms, its topography and its biota, rather than by human dictates; a region governed by nature, not legislature." ${ }^{4}$ Bioregionalists believe that nation-states and other administrative divisions are artificial constructs. ${ }^{5}$ In contrast with modern industrial society which effectively alienates people from the land, bioregionalists advocate "living-in-place," which means "following the necessities and pleasures of life as they are uniquely presented by a particular site, and evolving ways to ensure long-term occupancy of that site." They argue that "Living-in-place is an age-old way of existence disrupted in some parts of the world a few millennia ago by the rise of exploitative civilization, and more generally during the past two centuries by the spread of industrial civilization." 7

Bioregionalism, in essence, is the regional fulfillment of Aldo Leopold's "land ethic." As Stephanie Mills writes, "In a bioregion, the citizenry is more than human. Bioregionalism goes beyond ecology, in its enfranchisement of other life forms and land forms, and its respect for their destinies as intertwined with ours." ethic . . . enlarges the boundaries of the community to include soils, waters, plants, and animals, or collectively: the land. . . In short, a land ethic changes the role of Homo sapiens from conqueror of the land-community to plain member and citizen of it." 9

The process of becoming an ecological citizen is described by Berg and Dasmann as "reinhabitation":

Reinhabitation means learning to live-in-place in an area that has been disrupted and injured through past exploitation. It involves becoming native to a place through becoming aware of the particular ecological relationships that operate

${ }^{3}$ David Haenke, "A History of NABC," North American Bioregional Congress Proceedings, ed. Alexandra Hart (Forestville, Calif.: Hart Publishing, 1987), p. 38.

${ }^{4}$ Kirkpatrick Sale, Dwellers in the Land: The Bioregional Vision (San Francisco: Sierra Club, 1985), p. 43.

5 Peter Berg, "Growing A Life-Place Politics," Raise the Stakes 11 (1986): centerfold.

6 Peter Berg and Raymond Dasmann, "Reinhabiting California," Reinhabiting a Separate Country: A Bioregional Anthology of Northern California, ed. Peter Berg (San Francisco: Planet Drum Foundation, 1978), p. 217.

7 Ibid.

8 Stephanie Mills, "Planetary Passions: A Reverent Anarchy," CoEvolution Quarterly 32 (1981): 4 .

9 Aldo Leopold, "The Land Ethic," The Subversive Science: Essays Toward An Ecology of Man, ed. Paul Shepard and Daniel McKinley (Boston: Houghton Mifflin, 1969), p. 403. 
within and around it. It means understanding activities and evolving social behaviour that will enrich the life of that place, restore its life-supporting systems, and establish an ecologically and socially sustainable pattern of existence within it. Simply stated it involves becoming fully alive in and with a place. It involves applying for membership in a biotic community and ceasing to be its exploiter. ${ }^{10}$

The belief in the existence of natural regions, and its advocacy of a practical land ethic, are two key aspects of bioregionalism. A third aspect pertains to the regard that bioregionalists hold for local and regional cultures, which they see as the last holdout against a global monoculture:

Global Monoculture dictates English lawns in the desert, orange juice in Siberia, and hamburgers in New Delhi. It overwhelms local cultures and "raises" them regardless of the effects on cultural coherency or capacities of local natural systems. ${ }^{11}$

Stephanie Mills writes in relation to tourism that "the further we go in search of local colour and character, of the texture that makes human existence rich, the further behind we leave the possibility of discovering that texture in our own home places, and the more people upon whom we visit ourselves change to accommodate us." 12

Bioregionalism, as a cultural movement, "celebrates the particular: the unique and often indescribable features of a place. It celebrates this through visual arts, music, drama and symbols which convey the feeling of place."13 In particular, bioregionalists take inspiration from North American native cultures, which they see as expressing the spirit of specific natural regions.

\section{SOME PROBLEMS WITH BIOREGIONALISM}

Since its beginnings in the 1970s, the bioregional movement has picked up considerable momentum. The Ozark Area Community Congress (OACC) was officially convened in 1980 . Four years later, the Ozark bioregionalists played host to the first North American Bioregional Congress (NABC), representing over sixty groups continent-wide. This was followed, in 1986, by a second congress in northern Michigan, and a third in British Columbia in 1988. NABC IV is scheduled to occur in the Gulf of Maine in the summer of 1990.

Since 1981, similar congresses-called Fourth World Assemblies-have

${ }^{10}$ Berg and Dasmann, "Reinhabiting California," pp. 217-18.

11 Peter Berg, "Devolving Beyond Global Monoculture," CoEvolution Quarterly 32 (1981): 25.

12 Mills, "Planetary Passions," p. 5.

${ }^{13}$ Editorial, "An Integrating Idea," The New Catalyst 1, no. 2 (1986): 2. 
been held in Europe, the Sierra Club has published a major book on the subject, and the movement has been extensively written about in the alternative press. This "success" notwithstanding, unresolved questions remain. In reviewing the bioregional literature, one gets the sense that bioregionalists are somewhat confused. One wing of the movement wants to treat bioregionalism as a "science," while the other wing views it as an environmental ethic and as a cultural sensibility. The differences between these two approaches are not distinguished in the literature, but they inevitably lead to different conclusions.

The "scientific" approach is characterized by a tendency to reason from "first principles." It is also characterized by environmental reductionism and by a deification of the "laws of nature." The writer most guilty of these tendencies is Kirkpatrick Sale, author of the only book on bioregionalism issued by a major publisher. ${ }^{14}$

\section{BACK TO "FIRST PRINCIPLES"}

Sale is looking for the one dogma that provides the key to all human problems and he offers an "infallible" strategy for remedying them. He writes:

Facing the evidence of our ecological insanity, I take what . . comfort I can . . . from the belief that we have at our grasp the instrument-the philosophy, if you will-by which to begin to rescue, even now our beleaguered species. . . is

The problem, according to Sale, is that human institutions (economy, polity, society) are not in harmony with natural law. The solution is to discover, in nature, infallible first principles. Sale's book is organized around the progressive unfolding of these principles. In his introduction to "The Bioregional Paradigm," he gives us a preview of them, counterposing them to those of the "IndustroScientific Paradigm." His first principles include region, community, conservation, stability, self-sufficiency, cooperation, decentralization, complementarity, diversity, symbiosis, evolution, and division. ${ }^{16}$

Out of these truths, which Sale holds to be self-evident, a new world will be built. The task is to bring society into correspondence with "underlying geographic realities."

${ }^{14}$ Kirkpatrick Sale, Dwellers in the Land: The Bioregional Vision (San Francisco: Sierra Club, 1985).

${ }^{15}$ Ibid., p. 37

${ }^{16}$ Ibid., p. 50. As values, I agree with them wholeheartedly; when they're treated as "natural laws" I take offense. 


\section{SALE AS REDUCTIONIST}

According to Sale, decentralism is an "ecological law," from which flows "liberty," "equality," "efficiency," "welfare," and "security."17

At the right scale human potential is unleashed, human comprehension magnified, human accomplishment multiplied. . . . [T]he optimum scale is the bioregional, not so small as to be powerless and impoverished, not so large as to be ponderous and impervious, a scale at which at last human potential can match ecological reality. ${ }^{18}$

Sale neglects to mention that bioregions vary widely in size. The Great Lakes Basin is 244,000 square kilometers, and is host to thirty-six million people. ${ }^{19}$ It covers a larger area than Great Britain and France combined. Would the average citizen be innately better able to relate to an entity so massive than to the state, province, or country in which he or she already lives? In his belief that small is inherently beautiful, Sale forgets the monarchical character of such mini-states as Liechtenstein, and the feudal and militaristic character of various German principalities prior to German unification, many of which were far smaller than Sale's North American bioregions. Sale shares his penchant for reductionism with his intellectual mentor, Leopold Kohr. Kohr, a former professor at the University of Puerto Rico, has written that "there seems only one cause behind all forms of social misery: bigness. . . Whenever something is wrong, something is too big." ${ }^{20}$ One of Sale's critics has said that

[Sale] believes that the concept of scale is "at bottom, the single critical and decisive determinant of all human constructs, be they buildings, systems or societies." This statement shows by just how far Sale misses the essential understanding . . . that reified power (hierarchy or authority) is a more fundamental parameter . . . and that in actuality the parameter of scale tends to be related to the level of reified power in a society as a largely dependent variable. ${ }^{21}$

17 Ibid., pp. 96-97.

18 Ibid., p. 55.

19 Environment Canada, United States Environmental Protection Agency, Brock University, Northwestern University, The Great Lakes: An Environmental Atlas and Resource Book, 1987, pp. 3-5.

20 Leopold Kohr, The Breakdown of Nations (New York: E. P. Dutton, 1978), p. xviii.

21 Lev Chernyi, "The Bioregional Vision-Far-sighted or Myopic?" Anarchy 13 (1986): 9. 


\section{SALE'S TREATMENT OF NATURAL LAW}

According to Sale, ". . . it is in the diligent study of [the laws of nature] that we can best guide ourselves in reconstructing human societies for a bioregional world." 22 Sale believes that, by grasping the "laws of nature," human society can be restructured to make it more "natural" and intrinsically ecological, and that the breakdown of human institutions can be traced to their violation of natural law. In his discussion of cities, Sale writes:

Only rarely [in history] did agglomerations ever exceed [10,000 people], as with the capital cities of various empires, and even they typically lasted for less than a century before shrinking to smaller sizes, as if there was some process at work making cities inherently unstable and unsustainable. . . The giant city. . . may prove in the long run to be simply an uncontinuable experiment, a violation of the laws of human and biotic nature. . . . ${ }^{23}$

Sale describes large cities as "grand suction systems drawing their life from everywhere in the . . . surrounding world." ${ }^{24}$ This is true, but the converse-that "the small community has historically been the most efficient at using energy, recycling its wastes, reducing drawdown and adjusting to carrying capacity"-is not, as a look at the rapid depletion of resources in nineteenth century rural Ontario and elsewhere will attest. ${ }^{25}$ That small communities have always exhibited a "kind of unconscious wisdom. . . . [in] which people have been shown to solve social problems most harmoniously, to survive randomness and change most easily" is belied by the historical record. The capacity of many small communities for mean-spiritedness and conflict has been documented by sociologists and anthropologists alike. ${ }^{26}$

Sale also conflates the "laws" of social development with those of nonhuman nature in his discussion of the Irish famine of 1845 . He cites the famine as being an example of the ecological process of population "crash." That the Irish were forced by the English into single-crop dependence on the potato, and that they starved while supplies of food continued to be exported out of the country,

22 Sale, Dwellers in the Land, p. 49.

23 Ibid., pp. 64-65.

24 Ibid., p. 65.

25 See Donald Alexander, "The Decline of Hope Township, 1861-1961," unpublished paper; Sale, Dwellers in the Land, p. 65.

${ }^{26}$ See G. Hodge and M. A. Qadeer, Towns and Villages in Canada: The Importance of Being Unimportant (Toronto: Butterworths, 1983), p. 143; Napoleon A. Chagnon, "The Fierce People," Conformity and Conflict: Readings in Cultural Anthropology, ed. James P. Spradley and David W. McCurdy (Boston: Little, Brown and Co., 1974), pp. 402-10; Sale, Dwellers in the Land, p. 65. 
suggests that factors other than those involved in population crashes of nonhuman species were operative. ${ }^{27}$

Throughout the history of Western civilization, thinkers have purported to see in nature confirmation of the inevitability and "naturalness" of slavery, patriarchy, hierarchy, and war, as well as their converse: social justice, mutual aid, and human equality. ${ }^{28}$ Many feminist scholars and respected anthropologists have compellingly argued that much of human behavior is learned, not encoded in our genes. ${ }^{29}$ Given that nature can be used to "prove" just about anything, we should take great care in attributing to nature institutions and behaviors which are subject to a high degree of modification by culture. The "laws" of society cannot be reduced to those of biology any more than the laws of biology can be reduced to those of chemistry. ${ }^{30}$ Rosalind Williams, a reviewer of Sale, puts it well when she writes:

Maybe we need to increase our environmental consciousness, but we are also creatures of our racial, linguistic, religious, class and historical consciousness. Those other sources of our identity by no means fall along geographical lines. It's an old, old dream that a return to nature will simplify and clarify human affairs. . . . [T] make geography the basis of society is to oversimplify vastly the complexity of human nature. ${ }^{31}$

\section{WHAT IS A BIOREGION?}

There is no question that humanity needs to harmonize its relations with nature, that it needs to learn to live within ecological limits, but accepting this is a far cry from accepting that bioregionalism is the only way to achieve that end.

First of all, the definition of a bioregion is itself highly problematic. Berg defines bioregions as "unique life-places with their own soils and land forms, watersheds and climates, native plants and animals, and many other distinct natural characteristics." ${ }^{2}$ Bioregionalist Jim Dodge says that "the criteria most

27 Cecil Woodham-Smith, The Great Hunger: Ireland, 1845-1849 (New York: Harper and Row, 1962), pp. 75-77; Sale, Dwellers in the Land, pp. 25-26.

${ }^{28}$ Murray Bookchin, The Ecology of Freedom (Palo Alto, Calif.: Cheshire Books, 1982), pp. 27-33; Thomas Pawlick, “A Return to First Principles," Harrowsmith, June/July 1982, pp. 35-37; Peter Kropotkin, Mutual Aid (Boston: Porter Sargent, 1914).

${ }^{29}$ Simone de Beauvoir, The Second Sex (New York: Alfred A. Knopf, 1957); Marsha Hewitt, "Is Sexism Genetic?" Our Generation 16, no. 2 (1984): 7-14; Margaret Mead, Sex and Temperament in Three Primitive Societies (New York: Dell Publishing Co., 1969).

${ }^{30}$ Fritjof Capra, The Turning Point (Toronto: Bantam, 1983), pp. 102-03; Murray Bookchin, "Thinking Ecologically," Our Generation 18, no. 2 (1987): 6.

31 Rosalind Williams, "Earth Mother Knows Best" (review of Dwellers in the Land), New York Times Book Review, October 1985, pp. 15.

32 Peter Berg, "Growing a Life-Place Politics." 
often advanced for making bioregional distinctions are biotic shift, watershed, land form, cultural/phenomenological, spirit presences [!], and elevation." ${ }^{33}$ It should be noted that some of these criteria are mutually exclusive. For instance, a river watershed may yield a bioregion which is long and narrow, biotic shift (i.e., similarity of plants and animals in a given region) usually encompasses several watersheds, and using elevation can yield yet another type of bioregion.

J. Lewis Robinson, a noted geographer, has written that "Even though one accepts that regions exist, one should be aware that they are human intellectual constructs. They exist only in the minds of the persons who define, and accept, the criteria and characteristics of the region." 34 Geographer William Westfall has written that

There are no "natural" regions. Rather the land is divided into formal regions only as abstract criteria are applied to it. A similarity of topographical features is one set of criteria, and these criteria lead to a certain regional configuration. But these criteria do not create the only set of formal regions, let alone the most useful ones. By applying other criteria, it is possible to produce different, and more analytical, types of formal regions. ${ }^{35}$

This is not to say that regions are arbitrary. The boundaries of a watershed can be objectively determined, but watersheds are nested within watersheds. Thus, human subjectivity plays an important role in determining which level of aggregation is meaningful. As Berg and Dasmann write, "The final boundaries of a bioregion are best described by the people who have lived within it." 36

I have until recently lived in Peterborough, Ontario. Peterborough is situated in the Otonabee River watershed, which is more or less coterminous with the "Kawartha Lakes" region - a point of reference for local people and a one-time designated tourist region. The Kawarthas Lakes are part of the Lake Ontario basin which, in turn, is part of the Great Lakes Basin.

The Great Lakes Basin has been designated a bioregion by bioregionalists, despite the fact that it is composed of two physiographic regions, three soil zones, and three vegetation zones, none of which respect its boundaries. ${ }^{37}$ At the

${ }^{33}$ Jim Dodge, "Living by Life: Some Bioregional Theory and Practice," CoEvolution Quarterly 32 (1981): 8 .

${ }_{34}$ J. Lewis Robinson, Concepts and Themes in the Regional Geography of Canada (Vancouver: Talonbooks, 1983), p. 14.

35 William Westfall, "On the Concept of Region in Canadian History and Literature," Journal of Canadian Studies 15, no. 2 (1980): 7.

36 Berg and Dasmann, "Reinhabiting California," p. 218.

${ }^{37}$ Alexandra Hart, introduction to Stephanie Mills, "Cook's Tour," North American Bioregional Congress Proceedings (Forestville, Calif.: Hart Publishing, 1987), p. 6; Geoffrey J. Matthews and Robert Morrow Jr., Canada and the World: An Atlas Resource (Scarborough, Ontario: Prentice-Hall, 1985), pp. 24, 44, 52. 
smaller subregion level, the Lake Ontario basin can be divided into two physiographic regions (and soil zones), and two distinct vegetation and climate zones, each of which has an enormous impact on land-use patterns in their respective areas.

Even the "Kawartha Lakes" region is divided roughly in half by the boundary between the Canadian Shield (granite bedrock) and the Great Lakes-St. Lawrence Lowland (sedimentary limestone). On the shield, settlements are smaller and tourism and mining predominate. In the lowland, there is a higher density of population, and agriculture and industry predominate. Despite these significant differences, both physiographic portions are united in the popular regional designation, the "Kawartha Lakes."

I cite these overlapping regions not to discredit the bioregional concept, but to show that attempting to treat it as a dogma is counterproductive. Geographical boundaries are not defined solely by nature, but also by human use and perception. No matter what regional designation people adopt, the point is for them to "know the earth fully and honestly"- "the carrying capacities of its lands and waters; the places where it must not be stressed" and "the places where its bounties can best be developed." 38

\section{TOWARD A BIOREGIONAL SOCIETY}

While the size of our communities and the nature of our technology must be informed by an appreciation of natural processes, we can also argue for a different way of life based on uniquely human conceptions of the "good life" and on a free and open discussion of what contributes to its quality. Nature sets limits, but it does not dictate how we should treat one another, nor the kind of polity we should adopt. It can be argued that a society organized on the basis of bioregions is not only more ecologically sustainable, but also more intrinsically satisfying to human beings. In a world where people are increasingly complaining about a degraded environment, about lack of control over their lives, and the frenzied pace forced on them by a competitive, dog-eat-dog society, "quality of life" becomes an important argument militating for a different way of life.

For this reason, I prefer a conception of bioregionalism according to which it is defined in terms of an environmental ethic and a cultural sensibility that put the emphasis on what people choose to do, not on what people must do (or face the wrath of Mother Nature). A North American Bioregional Congress press release, while still speaking of "natural regions" as if they were self-evident, emphasizes the interrelatedness of environmental ethics and human-scale culture: "bioregionalism specifically values the local and the regional, seeing the

${ }^{38}$ Sale, Dwellers in the Land, p. 42. 
revitalization of local places, peoples and cultures as perhaps the only sure way of healing the planet." 39 This is essentially a restatement of Peter Berg's dictum that "For our heads to be everywhere our feet have to be some place." ${ }^{40}$ But the release also states that

each of us inhabits a "terrain of consciousness" determined in large part by the place we dwell in, the work we do, and the people with whom we share our lives. In this context, the re-creation of caring and sustainable human cultures becomes the "real work" of our time. ${ }^{41}$

This approach gets at the "quality of life" issue as well as the responsibility of humans to each other which must also become a part of the bioregional appeal.

\section{STRATEGIC CONSEQUENCES}

The two conceptions of bioregionalism I have outlined here imply quite different strategic orientations. The non-deterministic version acknowledges the extent to which nonbioregional forms of regionalism have come to the fore and is flexible enough to explore their potentiality as levers for the development of a socially and ecologically responsible attitude.

My study of south-central Ontario has revealed three forms of regional identification: municipal identification, urban catchment area identification, and local geographical identification. The third, while not identical to bioregional consciousness, is on a continuum with it. The first two, however, represent the triumph of human realities over those of nature; nevertheless, even these have a potentially liberational dimension.

It is an easily observed fact that people living in hamlets, villages, towns, and small cities have a strong identification with the communities in which they live and a strong sense of local pride. Moreover, despite the increasingly transient nature of today's human populations, people still have a vested interest in the town or township in which they pay property taxes, and in the county or regional municipality in which many decisions about waste management and land use are made. Murray Bookchin has identified the municipality as a possible arena for empowering local citizens and contesting the power of state (or provincial) and national governments. ${ }^{42}$ In addition, many citizens' groups have chosen the

${ }^{39}$ Christopher Plant (Steering Committee, North American Bioregional Congress), "What is Bioregionalism?" The Third North American Bioregional Congress, press release, 1 March 1988, p. 3.

40 Berg, "Devolving beyond Global Monoculture," p. 25.

41 Ibid., p. 3.

42 Murray Bookchin, The Rise of Urbanization and the Decline of Citizenship (San Francisco: Sierra Club, 1987), pp. 255-256. 
municipality as a convenient organizational unit for combatting ecologically hazardous projects. With renewed media attention being given to global ecological problems, the stage is set for environmental activists to involve themselves in local land-use issues and to demand that local planning contribute to a solution of such problems rather than exacerbating them further.

Though shaped by dependence on employment opportunities and shopping and recreational facilities, urban catchment area identification expresses the essential truth that what happens in rural areas is largely dictated by the metabolic changes initiated by the nearest city. Changing land-use patterns, rising real estate prices, pollution, and garbage all tend to radiate outward from urban centers, thus ensnaring rural residents in a web of common destiny with their urban counterparts. Any movement for regional sanity has to come to grips with the reality of urban areas, as bioregional authors like Peter Berg have begun to do in their exploration of the prospects for promoting a "green cities" movement. ${ }^{43}$

Local geographical identification - the sense of being "at home" in a specific place-is mediated by the history of settlement and land use. Brian Tokar has observed that eastern North Americans "generally live in highly socialized landscapes. .. . [R]elationships to the land are seen in social terms, whether one lives in a city or a small rural village." 44 Thus, in southern Ontario, people tend not to identify with a region in the abstract, but with an environment shaped by settlement. that

John Warkentin, a geographer from the western Canada has perceptively noted

Southern Ontarions seem indifferent about the character of their homeland. . . . [Ontario's] inhabitants display a lack of interest in the individuality or essential identity of the area. . . . [I]t is amazing to what extent the majority of the people of the peninsula have turned their backs on the [Great] lakes and are hardly conscious of them. ${ }^{45}$

This indifference can possibly be attributed to the anti-forest ethos of the early settlers, and the lack of continuous settlement (constant emigration and immigration). Moreover, for many people, "wilderness" is the shield country to the north where they have their cottages. Warkentin also draws attention to the minimal role that primary production plays in the life of the area relative to industry and

43 Shana Penn, "Green City: An Interview with Peter Berg," The Elmwood Newsletter, 3, no. 1 (1987); Peter Berg, "Urban Panel: Green City," North American Bioregional Congress Proceedings, ed. Alexandra Hart (Forestville, Calif.: Hart Publishing, 1987).

${ }_{44}$ Brian Tokar, "Exploring the New Ecologies: Social Ecology, Deep Ecology, and the Future of Green Political Thought," Alternatives 15, no. 4 (1988): 38.

45 John Warkentin, "Southern Ontario: A View from the West," The Canadian Geographer 10, no. 3 (1966): $157-58$. 
commerce, thus causing people's relationship to the land to be highly mediated. ${ }^{46}$

Fortunately, this attitude of indifference is beginning to change. Citizen groups like Great Lakes United and the Lake Ontario Organizing Network (LOON) are making their concerns known, and the phenomenon of "basin consciousness" is beginning to establish itself in Ontario. ${ }^{47}$ Bioregional boundaries cannot be pulled out of a textbook or derived from merely studying maps; bioregional definitions must (and will) emerge in practice. The emergence of the lake basins as a focal point as opposed to some other designation reflects the interaction of natural and cultural factors. The lakes were the means by which early European settlers colonized Upper Canada and supplied their needs, exporting wheat and timber. These lakes have now become the cesspool for the effluent of an ecocidal culture, even as many continue to depend on them for their drinking water. The dependence of human life on the integrity of lake ecosystems is refocusing attention on their centrality to the region, and provides a starting point for the development of a bioregional consciousness in the southern Ontario portion of the Great Lakes Basin.

\section{CONCLUSION}

My study of southern Ontario "place identification" and rural environmental movements suggests that a "municipal consciousness" and a bioregional consciousness are not at odds with each other, but reflect the interrelated natural and social realities that impinge on the individual. Rather than adopting an environmental determinist view that nature determines (or should determine) culture, or, conversely, a view which sees the role of the land as unimportant, we should opt for the dialectical concept of regions advanced by Lewis Mumford. He writes:

The human region ... is a complex of geographic, economic, and cultural elements. Not found as a finished product in nature, not solely the creation of human will and fantasy, the region, like its corresponding artifact, the city, is a collective work of art. ${ }^{48}$

Accepting the fact that "natural" regions have begun to give way in people's lives and consciousness to functional (i.e., cultural) regions, we should resolve to take advantage of whatever potential these hold for developing an attitude of

${ }^{46}$ Ibid., pp. 158-60, 165.

47 Dinah Watts, "Citizens Organize for Lake Ontario," Probe Post 11, no. 3 (1988): 10-11.

${ }^{48}$ Lewis Mumford, The Culture of Cities (New York: Harcourt Brace Jovanovich, 1938), p. 367. 
ecological and social responsibility. At the same time, making use of concerns about environmental and quality of life issues, we can strive to cultivate bioregional consciousness-wherever possible bringing it into the cultural mainstream-such that the health of the "land community" becomes an ethical standard for human beings everywhere. 